\title{
АНАЛИЗ ПРОСРОЧЕННОЙ ЗАДОЛЖЕННОСТИ: ВОЗМОЖНОСТЬ ПРИМЕНЕНИЯ НОВЫХ ИНСТРУМЕНТОВ
}

\author{
(C) 2019 Антонова O.B. \\ кандидат экономических наук, доцент Департамента учета, анализа и аудита \\ Финансовый университет при Правительстве Российской Федерации, Россия, Москва \\ E-mail: olgavit01@yandex.ru
}

На сегодняшний день весомой проблемой как для кредитных организаций, так и для коллекторских агентств является установление действительной стоимости розничного портфеля и в особенности задолженности по кредитам физических лиц. Актуальность данной статьи обуславливается тем, что в последние годы исследований, научных и практических трудов по данной проблеме сравнительно немного, несмотря на серьезность этого вопроса.

Ключевые слова: бухгалтерский учет, отчетность, просроченная задолженность, анализ дебиторской задолженности

Кредитование населения сегодня является неотъемлемой частью российской экономики. Наряду с активным привлечением и наращиванием портфеля перед отечественными розничными банками, появляются насущные вопросы: какова возвратность просроченной задолженности и как ее повысить? Одним из возможных решений является продажа проблемной части портфеля сторонней организации. Под влиянием совокупных факторов возникает новый элемент экономических отношений - коллекторское агентство. Данная организация, которая является контрагентом кредитных организаций при сделке по уступке прав требования, а также по агентскому сопровождению, как никто другой заинтересована в реальной стоимости портфеля и максимальном возврате просроченной задолженности.

Все это является предпосылкой для создания нового направления в финансовом анализе, которое можно назвать коллекторский аудит, предполагающий комплексный анализ системы управления риском, при которой был создан розничный портфель. Соответственно, пользователями результатов такого аудита могут быть: само коллекторское агентство, аудируемый банк, инвесторы банка, Банк России, иные пользователи.

Цель данного аудита - формирование мнения об эффективности управления рисками в системе кредитования частных лиц. Это мнение можно выразить через стоимость розничного портфеля. Хотя, такое изложение цели в некоторой степени разнится от выраженной в правиле (стандарте) № 1 аудиторской деятельности - мнение аудитора может способствовать росту доверия к финансовой (бухгалтерской) отчетности, пользователь не должен принимать данное мнение ни как выражение уверенности в непрерывности деятельности аудируемого лица в будущем, ни как подтверждение эффективности ведения дел руководством данного лица. Но, если данная информация необходима и используется, например, аудируемым банком, либо каким-либо надзорным органом, то цель можно вывести таким образом - с помощью установления реальной стоимости портфеля позволительно сделать вывод о достаточности резерва по портфелю однородных ссуд.

Коллекторский аудит можно охарактеризовать следующими принципами:

- независимость;

- объективность;

- честность;

- профессиональная компетентность и добросовестность;

- конфиденциальность.

А принципами, которые определяют специфику данного аудита, являются:

- дефицит информации;

- приоритет количественных методов в анализе;

- отсутствие единых стандартов управленческого учета;

- высокая доля показателей, образованных на основе субъективных оценок.

Чтобы раскрыть эти принципы, необходимо рассмотреть особенности процедур данного 
вида аудита.

Так как рассматриваемое направление аудита только проходит процесс становления и внедрения, аудируемый банк, исходя из соблюдения банковской тайны, а также поскольку нет единых критериев учета качества управления рисками портфеля, будет предоставлять минимальный объем информации для проведения проверки. Также при проверке может рассматриваться не весь портфель, а только его часть. Поэтому особое внимание необходимо уделять выбору источника информации. Источники информации могут быть:

1. Общедоступные:

- официальная отчетность;

- добровольно раскрываемая информация.

2. Закрытые:

- данные внутреннего управленческого учета;

- факты предыдущих проверок.

Информация, которую получают из общедоступных источников, чаще всего сильно искажена, носит обобщенный характер, помогает получить выводы о заключительном влиянии условий, в котором формировался портфель, о результатах процедур по управлению рисками.

Информация, которую получают из закрытых источников носит практический характер, более приближенно к действительности отражает мнение экспертов о портфеле. Но именно по этой причине она может быть очень субъективной. Эти данные показывают влияние отдельных факторов и условий образования портфеля, осуществление процедур по управлению риском. Но, чтобы ее качественно и достоверно оценить, необходимы утвержденные нормы ее содержания, так как каждая кредитная организация имеет и применяет свои собственные показатели, систему учета и контроля эффективности антирисковой политики, в частности, при управлении рисками в розничном портфеле. В итоге, получаемая информация выходит искаженной, неполной при трансформации данных под стандарты проверяющей организации, а также препятствием является и отсутствие основных показателей.

Значительную роль имеют требования к конечному результату проверки. Наиболее доскональным итогом аудита может быть обстоятельная, полная, всесторонняя, количественно измеримая информация о портфеле и отдельных элементах:
- текущая и прогнозная эффективность управления риском невозврата. Показывает не только эффективность, но и перспективы работы с портфелем;

- степень доверия к результатам проверки.

Количественную трактовку указанных характеристик можно показать в виде стоимостных показателей - стоимость портфеля, сумма прибавочного эффекта от улучшения системы управления рисками невозврата, величина возможных потерь в случае ошибок в результатах проверки.

Чтобы получить качественные результаты, в ходе проверки необходимо:

- формировать выборку по самым проблемным участкам в управлении риском портфеля. Для этого перед программой аудита надо проделать дополнительный анализ портфеля, чтобы выявить эти места;

- формировать выводы, исходя из нескольких источников данных;

- учитывать соответствие используемых процедур, их применимость в каждом случае при анализе отдельных составляющих риск-менеджмента.

Учитывая все нюансы, оценку розничного портфеля можно проводить следующими методами:

1. Дедуктивный. В самом начале определяется текущая доля возможного невозврата, затем проводится поиск и вычленение реальных компонентов риска и управляемых факторов риска невозврата, их процент значимости. Этот метод применим, когда есть только обобщенные показатели и дефицит дополнительной статистической информации.

2. Индуктивный. Анализируя данные отдельных элементов риск-менеджмента, можно сказать об адекватности применяемых антирисковых процедур и сделать вывод о текущем уровне риска невозврата. Этот метод применим, когда у проверяющего есть разрозненная информация об отдельных компонентах системы управления рисками (при ограниченном допуске к данным).

3. Эталонный. В данном случае вся информация об оцениваемом портфеле подгоняется под форматы уже ранее проверенного портфеля (эталона), проводится сравнение, сопоставление данных и делается соответствующий вывод. Это метод применим, когда у проверяющего есть большой опыт успешных проверок, а также при 
сопоставимости данных проверяемого и эталонного портфелей.

4. Скоринговый. Данные о каждой ссуде в портфеле переводят в стандартизированный вид, затем с помощью программного обеспечения обрабатывается массив данных и анализ свойств каждого кредита по скоринговой модели. Этот метод применим при возможности предоставления данных в определенном формате.

Специфика коллекторского аудита на сегодняшний день во многом предопределена особенностями развития национального рынка розничного кредитования, и скорее всего, каки- е-то отдельные составляющие и отличительные особенности могут утратить свою значимость со временем. С развитием и распространением института бюро кредитных историй присутствует большая вероятность решения проблемы дефицита информации, достоверности и стандартов учета отдельных показателей эффективности управления риском невозврата в розничном портфеле. Но данная тенденция развития довольно растянута во времени. Но, несмотря на все изменения и перипетии, сущность и принципиальное содержание данного вида аудита должны остаться неизменными.

\section{Библиографический список}

1. Петров А.M., Полоус Е.А. Повышение транспарентности показателя дебиторской задолженности в отчетности / Международный бухгалтерский учет. 2011. № 6 (156). С. 2-12.

2. Петров А.М., Лымарь М.П. Сравнительная характеристика основных положений законов, регулирующих бухгалтерский учет в Китае и России / Международный бухгалтерский учет. 2013. № 40 (286). С. 52-60.

3. Петров А.М. Контроль за движением дебиторской и кредиторской задолженности / Современный бухучет. 2004. № 9. С. 38.

4. Бабаев Ю.А., Друцкая М.В., Кеворкова Ж.А., Листопад Е. Е., Петров А.М. Бухгалтерский учет, анализ и аудит внешнеэкономической деятельности. Учебник для студентов обучающихся по специальности 080109 «Бухгалтерский учет, анализ и аудит» / под редакцией Ю.А. Бабаева. Москва, 2010.

5. Петров А.М., Мельникова Л.А. Теоретические аспекты учета калькулирования себестоимости продукции / Экономические науки. 2013. № 102. С. 145-148.

6. Петров А.М., Коняхин А.Н. Учетная политика при подготовке первой отчетности согласно МСФО / Международный бухгалтерский учет. 2013. № 11 (257). С. 2-15.

7. Бабаева З.Д., Гетьман В.Г., Гришкина С.Н., Домбровская Е.Н., Керимов В.Э., Неселовская Т.М., Рожнова О.В., Сиднева В.П., Петров А.М., Блинова У.Ю. Бухгалтерский учет. Учебник / Москва, 2017. Сер. Бакалавриат (2-е издание, переработанное и дополненное)

8. Петров А.М. Актуальные вопросы экономико-правового регулирования и классификации корпоративных систем / Проблемы современной экономики. 2009. № 1 (29). С. 182-186.

9. Петров А.М., Мельникова Л.А. Формирование отчетности в соответствии с требованиями МСФО как объективная необходимость на современном этапе развития экономики РФ / Проблемы современной экономики. 2017. № 2 (62). С. 105-107.

10. Петров А.М. Общественное питание 6 в 1: учетная политика, документооборот, калькулирование себестоимости, бухгалтерский учет, налоги, отчетность / А.М. Петров. Москва, 2011. Сер. Полное руководство бухгалтера

11. Петров А.М. Бухгалтерский учет основных средств / Бухгалтерский учет в издательстве и полиграфии. 2012 . № 3 (159). C. 2-22.

12. Петров А.М., Лымарь М.П. Сравнительная характеристика основных положений законов, регулирующих бухгалтерский учет в Китае и России / Все для бухгалтера. 2014. № 1 (277). С. 36-43. 